\title{
Quality of life of patients with lung cancer
}

This article was published in the following Dove Press journal:

OncoTargets and Therapy

29 February 2016

Number of times this article has been viewed

\author{
Jacek Polanski' \\ Beata Jankowska-Polanska² \\ Joanna Rosinczuk ${ }^{3}$ \\ Mariusz Chabowski ${ }^{4}$ \\ Anna Szymanska- \\ Chabowska $^{5}$ \\ 'Lower Silesian Oncology Center, \\ Home Hospice, ${ }^{2}$ Department \\ of Clinical Nursing, ${ }^{3}$ Department \\ of Nervous System Diseases, \\ Department of Clinical Nursing, \\ ${ }^{4}$ Division of Nursing in Surgical \\ Procedures, Department of \\ Clinical Nursing, Faculty of Health \\ Science, ${ }^{5}$ Department of Internal \\ Medicine, Occupational Diseases \\ and Hypertension, Wroclaw Medical \\ University, Wroclaw, Poland
}

\begin{abstract}
Lung cancer is the major cause of oncologic-related death worldwide. Due to delayed diagnosis, 5-year survival rate accounts for only 15\%. Treatment includes surgery, adjuvant chemotherapy, and radiation therapy; however, it is burdened by many side effects. Progress of the disease, severity of its symptoms, and side effects decrease significantly the quality of life (QoL) in those patients. The level of self-assessed QoL helps in predicting survival, which is especially important among patients receiving palliative care. Patients assess their functioning in five dimensions (physical, psychological, cognitive, social, and life roles), severity of symptoms, financial problems, and overall QoL. The QoL in lung cancer patients is lower than in healthy population and patients suffering from other malignancies. It is affected by the severity and the number of symptoms such as fatigue, loss of appetite, dyspnea, cough, pain, and blood in sputum, which are specific for lung tumors. Fatigue and respiratory problems reduce psychological dimension of QoL, while sleep problems reduce cognitive functioning. Physical dimension (related to growing disability) decreases in most of the patients. Also, most of them are unable to play their family and social roles. The disease is a frequent reason of irritation, distress, and depression. Management of the disease symptoms may improve QoL. Controlling the level of fatigue, pulmonary rehabilitation, and social and spiritual support are recommended. Early introduction of tailored palliative treatment is a strategy of choice for improvement of QoL in lung cancer patients.
\end{abstract}

Keywords: lung cancer, prognostic factor, quality of life, adverse events, survival, public health medicine

\section{Introduction}

Lung cancer is among the most common malignancies in the US with over 219,000 new cases and over 159,000 deaths reported in 2009. Only 16\% of early-stage lung tumors are diagnosed; therefore, 5-year survival rate accounts for only $15 \% .{ }^{1}$ Poland is among the countries with the highest rate of mortality and morbidity. Every year, $\sim 20,000$ people die due to lung cancer. Most of the patients $(\sim 80 \%)$ have distant metastases at the diagnosis.

Clinical classification distinguishes two groups of primary malignant tumors of the lungs: non-small-cell lung cancer (NSCLC) and small-cell lung cancer (SCLC). NSCLC accounts for over $80 \%$ of all lung cancers and is the major cause of death worldwide. The remaining $20 \%$ of patients with lung tumors are diagnosed as SCLC. Their average survival is between 12 and 16 months for limited stage and between 7 and 11 months for extensive stage.

At early stages of NSCLC, recommended surgical treatment includes anatomical resection of lung tissue (lobectomy) combined with removal of lymph nodes. Overall 5 -year survival rate is 55\%-77\% for patients with stage I NSCLC treated with lobectomy, while it is only $6 \%$ for nonoperated patients. Administration of the adjuvant chemotherapy after surgery prolongs survival. Radiation therapy is administered as a
Correspondence: Mariusz Chabowsk Department of Surgery, 4th Military Teaching Hospital, 5 Weigla Street, 50-98I Wroclaw, Poland

Tel +48 26I 660247

Fax +48 26I 660245

Email mariusz.chabowski@gmail.com
OncoTargets and Therapy 2016:9 1023-1028

Dovepress

http://dx.doi.org/10.2147/OTT.S100685 (c) (1) (8) 2016 Polanski et al. This work is published and licensed by Dove Medical Press Limited. The full terms of this license are available at https://www.dovepress.com/terms.php (c) ${ }_{\mathrm{BY}} \mathrm{NC}$ and incorporate the Creative Commons Attribution - Non Commercial (unported, v3.0) License (http://creativecommons.org/licenses/by-nc/3.0/). By accessing the work you hereby accept the Terms. Non-commercial uses of the work are permitted without any further permission from Dove Medical Press Limited, provided the work is properly attributed. For permission for commercial use of this work, please see paragraphs 4.2 and 5 of our Terms (https://www.dovepress.com/terms.php). 
therapeutic option in patients with stage I and II NSCLC with contraindications for surgery due to comorbidities, because it allows a 55.8\% 3-year survival rate to be achieved, along with moderate side effects. In patients with advanced lung cancer (stage III and IV), early initiation of palliative treatment allows for improvement in the quality of life (QoL).

Despite significant advances in oncology, results of the treatment of lung cancer are still unsatisfactory, mainly due to late diagnosis, old age of patients, concomitant diseases, and as a consequence, limited therapeutic options. ${ }^{2}$ Symptomatic treatment remains a challenge for palliative care teams.

Both malignant disease and its therapy influence significantly the QoL, well-being, and daily social functioning. QoL is determined by severity of disease symptoms, such as chronic cough, dyspnea, and pain in the chest. Additionally, fatigue, weight loss, cachexia, and general weakness appear in metastatic patients. Persistent symptoms lead to disorders in physical functioning, while diagnosis and complex treatment adversely affect psychological functioning.

\section{Quality of life}

QoL along with assessment of efficacy and safety of treatment became the basic aim of therapeutic approach. Selfassessed QoL is based on a subjective scale of severity of symptoms. It supplements clinical evaluation and helps predicting survival. Braun et al's studies proved that initial assessment of QoL along with evaluation of physical condition is a source of important prognostic information in patients with lung cancer., ${ }^{3,4}$ They complement laboratory and diagnostic examinations.

In clinical studies on consequences of chronic diseases, the principle of sole biological assessment is increasingly abandoned in favor of the multifactorial evaluation which includes emotions, mood, and ability to function in daily life. The assessment performed by the patient indicates limitation in daily activities due to illness or its treatment. Studies on QoL show patient's feelings which can differ from professional medical knowledge. Assessment carried out by the patient is a valuable source of information, and it can be helpful during therapeutic discussions. Moreover, it can indicate the patient's needs that are unrecognized by the physician. QoL measurement seems to be especially important among patients receiving long-term care services. In this group, treatment may be limited to palliative care because of incomplete return to full health or incurable condition due to severity of symptoms.

\section{Health-related QoL}

Health-related QoL (HRQoL) is difficult to define; therefore, definitions vary. Ebrahim claims that HRQoL is determined by QoL and modified by physical impairment, limitation of functional state, perceptions, and opportunities of social activity. ${ }^{5}$ It depends on type of disease, treatment, and longterm follow-up. The majority of researchers refer to the definition given by the World Health Organization where HRQoL denotes complex self-assessment including physical health, psychological state, level of independence and dependency on others, social relationships, and religion and personal beliefs. ${ }^{5}$ In general assessment of health condition, an important role is played by mental and social resources that patients possess before the onset of the disease and the environmental response to a change in the condition of their health. The most important factors include material resources, education, intellectual resources, marital status, level of social support, and availability and quality of medical services.

The World Health Organization recognized the following indicators of QoL: ability to play and modify social roles in life, adaptation, and mental well-being. According to Siegrist and Junge, QoL encompasses physical dimension (pain and disability), psychological dimension (anxiety and depression), and social dimension (degree of isolation and ability to perform social roles). ${ }^{6}$ When conducting researches, attention should also be paid to functioning ability, individuals' perception of their situation, and disease symptoms. ${ }^{6}$ The factors that influence the QoL negatively include negative health behaviors, exposure to stressful situations, and strategies to overcome them.

\section{QoL in patients with lung cancer}

QLQ-C30 questionnaire and QLQ-LC13 module developed by European Organization for Research on Treatment of Cancer are the most frequently used research tools in patients with lung cancer. Questions from those questionnaires relate to patients' functioning, severity of symptoms, financial problems resulting from the disease and treatment, and overall QoL. The functioning of patients is considered in the following dimensions: physical, psychological, cognitive, social, and life roles. Assessment of physical functioning relates to difficulties in walking, need for help, and carrying things. Assessment of psychological functioning is based on questions about feelings of tension, irritation, and depression as well as the frequency of worrying during the past days. Cognitive dimension assessment consists of questions concerning difficulties in remembering and attention, while in dimension of life roles, limitations in either doing work or pursuing hobbies are evaluated. The questionnaire also asks about symptoms specific for lung cancer such as dyspnea, cough, hemoptysis, loss of appetite, nausea and vomiting, diarrhea, constipation, 
fatigue, sleep disorders, pain, difficulty with swallowing, and hair loss. ${ }^{7}$

QoL in patients with neoplastic disease depends on type of cancer, tumor localization, stage, type of treatment, and prognosis for cure and survival. Most of the papers from the literature report that the QoL in patients with lung cancer is lower than in healthy population. ${ }^{8}$ Additionally, it can be influenced by biological sex. Men reported higher QoL than women in social and psychological domain. ${ }^{9}$

Currently, authors of many publications hold the debate on the influence of age on the QoL. Some researchers reported poor results in elderly people and those who smoke (at present or in the past). ${ }^{8,10}$ On the contrary, Zimmermann et al found that elderly people reported higher QoL than younger patients. These outcomes may be explained by a traumatic reaction for the diagnosis, lack of acceptance at the time of diagnosis, and performance of important professional and family roles. ${ }^{11-13}$ According to Zimmermann et al, people with low income reported lower QoL in social dimension, while employed or retired patients reported higher QoL in physical and emotional dimension than unemployed and disabled patients. ${ }^{12}$

\section{Symptoms of the disease}

On the basis of Lung Cancer Symptoms Scale, Iyer et al proved that the most frequent symptoms include fatigue (98\%), loss of appetite (98\%), respiratory problems (94\%), cough (93\%), pain (90\%), and blood in sputum $(70 \%)$. Additionally, correlation analysis showed that the greater the severity of symptoms, the lower the QoL. Symptoms such as loss of appetite, fatigue, pain, and dyspnea reduce the QoL the most. ${ }^{14}$ Furthermore, other studies show that the more the symptoms of the disease, the lower the QoL. ${ }^{10,15,16}$ Increasing fatigue, dyspnea, cough, and pain reduce emotional dimension of QoL, while problems with night rest impair cognitive functioning. ${ }^{17}$

In the study conducted by Nowicki et al, in all 30 patients suffering from lung cancer and treated surgically, reduced physical dimension of QoL was observed; however, they were able to perform their daily life activities by themselves. Physical dimension gradually increased after operation, but making more intensive effort was still impossible 3 months following the surgery. Psychological dimension was good, but only every fourth patient could perform life roles successfully. In most of the patients, the disease was a reason for irritation and distress, and one-third of them complained about the impairment of family and social life. ${ }^{18}$

In the literature, limitations in social life of patients with lung cancer are explained by severe feeling of fatigue.
Nowicki et al reported that fatigue was recognized as the most severe side effect of oncologic therapy by $70 \%$ of the patients $-66 \%$ claimed that problems caused by fatigue impair daily life more than those caused by pain. ${ }^{18}$ Another symptom that influenced the assessment of QoL was pain in the chest and problems with swallowing, reported by every fifth subject. Also, in Cooley's work, pain and fatigue were the most important symptoms leading to disturbances in the course of treatment. ${ }^{19}$ Gift et al found that fatigue, nausea, weakness, loss of appetite, weight loss, and vomiting were the most frequently mentioned symptoms that impaired daily functioning in patients with recently diagnosed lung cancer. The same cascade of symptoms was equally severe at 3 and 6 months following diagnosis. Additionally, factors such as stage of disease, comorbidities, and administration of chemotherapy played important roles in relation to daily functioning. ${ }^{20}$

Studies including patients with inoperable lung cancer allowed for the identification of a group of nine important symptoms in terms of QoL assessment. They were as follows: perception of self, difficulty with breathing, pain, sleep disorders, cough, intestinal disorders, loss of appetite, fatigue, and appearance. Tishelman et al proved that the most important symptom at diagnosis is the perception of self and that the breathing problems are observed only a month later. ${ }^{21}$ Also, Butt et $\mathrm{al}^{22}$ assume fatigue as the most frequently occurring and the most important symptom in patients with lung cancer.

Ostlund et al showed in a group of Swedish patients that emotional functioning and fatigue were significant predictors of the overall QoL. ${ }^{23}$ Similar outcomes were presented by Dagnelie et al. ${ }^{24}$ They found that fatigue was a more important negative predictor of QoL in comparison with other lung cancer-specific symptoms. Chronic fatigue is related to the difficulties with falling asleep and insufficient night and day rest. ${ }^{1}$

Three months following surgery, patients complained about moderate dyspnea, which had an average impact on QoL assessment. Only every tenth patient denied cough. They sometimes observed blood in sputum. ${ }^{18}$ Sleep disorders appeared in a half of responders, and they could be related to both the underlying disease and care of their own health.

Financial problems are common among the patients with lung cancer. Nowicki et al reported that they appeared often in this group and had an important impact on QoL assessment, while Wachowicz and Furmanik claimed that they appeared only during the early period of treatment. ${ }^{18,25}$

Leppert studied patients with advanced lung cancer: 50 received home palliative care, and 25 were hospitalized at the inpatient palliative care unit. All of them experienced 
problems during tiring activities, almost all of them reported fatigue during short and long walks, and a majority of them very often rested in bed or armchair during the day and required help from caregivers to perform basic daily activities. Over $90 \%$ of the studied patients often, or very often, complained about limitations in performing occupational roles or pursuing hobbies. Additionally, patients at a hospice center reported limitations in family and social life. All of the studied subjects felt tired and depressed. Lowering of cognitive functions (memory and attention) and significant lowering of social dimension of QoL were observed in all patients treated in the inpatient settings. ${ }^{2}$

Significant factors limiting QoL are the disease stage and the change of therapeutic schedule which patients often relate to poor prognosis. ${ }^{11}$ Results of studies show that prolongation of life due to administered treatment is often associated with side effects. ${ }^{26}$ Thus, therapeutic success should be determined not only by efficacy and prolongation of survival but also by obtaining a satisfactory level of the self-assessed QoL.

\section{Therapeutic options}

Results of many studies indicate improvement in functioning with the use of constant therapeutic regimen. In Nowicki et al's study, the QoL gradually improved after surgical treatment, while in Kubaszewska et al's study, in patients with lung cancer treated with brachytherapy, improvement was achieved in terms of somatic disorders; physical, cognitive, and social functioning; and overall assessment of QoL. ${ }^{18,27}$

The studies performed by Karczmarek-Borowska et al included patients with NSCLC and treated with chemotherapy. In this group, researchers found a negative correlation between the number of chemotherapy cycles and the level of QoL - the longer the chemotherapy treatment, the lower the QoL - especially in people older than 65 years. ${ }^{28}$ Moreover, patients had problems with performance of occupational and family roles as well as doing simple daily duties. People below 65 years of age showed more limitations in terms of psychological functioning, while those above 65 years of age showed more limitations in terms of physical, social, and occupational functioning. ${ }^{28}$

\section{Psychological problems (depression and anxiety)}

The level of perceived depression and anxiety is another QoL predictor. Cancer patients often experience psychological distress during and after oncologic therapy. Zabora et al performed studies in order to compare the level of stress in patients with 14 types of cancer. The results showed the highest intensity of stress among patients with lung cancer. ${ }^{29}$ The studies revealed that one in four people experienced depression or other psychological problems during treatment. ${ }^{30}$ Depression affects an average of $23 \%-40 \%$ of patients with lung cancer, and fear and anxiety $16 \%-23 \%$ of them. ${ }^{31,32}$

Anxiety and depression are related to the QoL of patients with lung cancer. The level of anxiety often increases during therapy (chemotherapy), which is related to decrease in QoL. ${ }^{33}$ Patients with SCLC experience depression symptoms of greater intensity than patients with NSCLC (25\% vs 9\%). Additionally, intensity of depression symptoms is associated with loss of possibility for proper functioning. ${ }^{32}$ Depression is a predictor of shorter survival in patients with recently diagnosed lung cancer. Pirl et al documented that early start of palliative care decreases intensity of depression symptoms; however, no influence of depression therapy on survival improvement was found. ${ }^{34}$

\section{Sense of coherence}

The idea of coherence and acceptance in the fight against chronic disease is highly emphasized. According to literature, a man possesses a certain, relatively constant feature called coherence. Sense of coherence is a feature that influences the way people fight with a disease and strategies they choose the most often. Studies available in the literature show that sense of coherence in patients with lung cancer is decreased both during undergoing diagnostic examinations and waiting for operation. ${ }^{35}$ Patients with lung cancer employ the most common active coping strategies to get through the disease. Problem-focused coping allows reducing emotions related to stress and taking proactive approach in the therapeutic process. Researchers confirmed the association between sense of coherence and coping styles with the disease higher level of coherence limited emotion-focused coping and allowed the patients to better cope with the disease and disease-related limitations.

Studies on assessment of coping with the oncologic disease and its influence on the QoL are rare. Porter et al revealed that high self-efficacy and cognitive abilities in patients with early-stage lung cancer reduce symptoms and level of stress, and improve physical dimension of QoL. ${ }^{36}$ In Liao et al's research, the high level of the skills of coping with the disease was associated with higher QoL assessment in terms of emotional and cognitive functioning. ${ }^{11}$ The different factors affecting QoL are depicted in Table 1. 
Table I The factors influencing the quality of life (QoL)

\begin{tabular}{|c|c|}
\hline Factors lowering QoL & Factors raising QoL \\
\hline Women ${ }^{9}$ & Men \\
\hline Elderly people above 65 years of age $e^{8,10,28}$ & Younger people below 65 years of age \\
\hline Smokers 8,10 & Nonsmokers \\
\hline Low income ${ }^{12}$ & Employed or retired \\
\hline Severe symptoms: chronic fatigue, dyspnea, cough, pain, nausea & Mild symptoms \\
\hline \multicolumn{2}{|l|}{ and vomiting, weight loss, loss of appetite ${ }^{|4,18-2|}$} \\
\hline More symptoms ${ }^{10,15,16}$ & Less symptoms \\
\hline Chemotherapy ${ }^{28}$ & Surgical treatment ${ }^{18}$ \\
\hline Greater intensity of anxiety and depression ${ }^{33}$ & Anxiety and depression of a lesser intensity \\
\hline Skills of coping with disease" & Indifference and inactivity \\
\hline
\end{tabular}

\section{Possibilities of QoL improvement in patients with lung cancer}

The basis for improving the QoL in patients suffering from lung cancer is limited by the number and severity of disease symptoms, especially fatigue, pain, and dyspnea. Multidimensional approach recommends controlling the level of fatigue with the use of pharmacological and nonpharmacological modalities including physical activity, saving energy, rest, sleep, reducing stress, and proper $\operatorname{diet}^{37}$ (Table 2). Recommended strategy for QoL improvement and reduction of fatigue is pulmonary rehabilitation. ${ }^{38}$

Among other efficient strategies for improvement of QoL, social support and praying to God are described. Support has the significant impact on functioning of the patient and reduces intensity of symptoms such as fear, anxiety, and depression. Social contacts provide positive experiences and the sense that life is more predictable and stable. The closeness with kind people gives the sense of security and acceptance, and helps to reduce anxiety and helplessness. Moreover, patients who receive support are more compliant with medical recommendations and more involved in the process of treatment.

Identification of factors influencing QoL, that the patient regards as important, is crucial. It should be emphasized that tailored palliative treatment is the best strategy for improvement of QoL. Early psychological, social, and spiritual support reduces risk of the psychosocial consequence of the disease..$^{39}$

Table 2 The improvement of the quality of life

Identification of factors influencing quality of life

Limitation of the number and severity of disease symptoms (fatigue, pain, and dyspnea) with the use of pharmacological and nonpharmacological modalities

Psychological, social, and spiritual support

\section{Disclosure}

The authors declare no conflicts of interest in this work.

\section{References}

1. John L. Self-care strategies used by patients with lung cancer to promote quality of life. Oncol Nurs Forum. 2010;37(3):339-347.

2. Leppert W. Jakość życia chorych na zaawansowanego raka płuca objętych opieką paliatywną, stacjonarną i domową [Quality of life in patients with advanced lung cancer at home palliative care at the in-patient palliative care unit]. Medycyna Paliatywna. 2010;1:25-34. Polish.

3. Braun DP, Gupta D, Staren ED. Quality of life assessment as a predictor of survival in non-small cell lung cancer. BMC Cancer. 2011;11:353.

4. Efficace F, Bottomley A, Smit EF, et al. Is a patient's self-reported health-related quality of life a prognostic factor for survival in nonsmall-cell lung cancer patients? A multivariate analysis of prognostic factors of EORTC study 08975. Ann Oncol. 2006;17(11):1698-1704.

5. Ebrahim S. Clinical and public health perspectives and applications of health-related quality of life measurement. Soc Sci Med. 1995; 41(10):1383-1394.

6. Siegrist J, Junge A. Conceptual and methodological problems in research on the quality of life in clinical medicine. Soc Sci Med. 1989; 29(3):463-468.

7. Tomaszewski KA, Püsküllüoğlu M, Biesiada K, Bochenek J, Nieckula J, Krzemieniecki K. Validation of the Polish version of the EORTC QLQC30 and the QLQ-OG25 for the assessment of health-related quality of life in patients with esophagi-gastric cancer. J Psychosoc Oncol. 2013; 31(2):191-203.

8. Lemonnier I, Baumann C, Jolly D, et al. Solitary pulmonary nodules: consequences for patient quality of life. Qual Life Res. 2011; 20(1):101-109.

9. Lövgren M, Tishelman C, Sprangers M, Koyi H, Hamberg K. Symptoms and problems with functioning among women and men with inoperable lung cancer - a longitudinal study. Lung Cancer. 2008;60(1): 113-124.

10. Hermann CP, Looney SW. Determinants of quality of life in patients near the end of life: a longitudinal perspective. Oncol Nurs Forum. 2011;38(1):23-31.

11. Liao YC, Shun SC, Liao WY, Yu CJ, Yang PC, Lai YH. Quality of life and related factors in patients with newly diagnosed advanced lung cancer: a longitudinal study. Oncol Nurs Forum. 2014;41(2):E44-E55.

12. Zimmermann C, Burman D, Swami N, et al. Determinants of quality of life in patients with advanced cancer. Support Care Cancer. 2011;19(5): 621-629.

13. Mor V, Allen S, Malin M. The psychosocial impact of cancer on older versus younger patients and their families. Cancer. 1994;74:2118-2127.

14. Iyer S, Taylor-Stokes G, Roughley A. Symptom burden and quality of life in advanced non-small cell lung cancer patients in France and Germany. Lung Cancer. 2013;81(2):288-293. 
15. Gralla RJ. Quality-of-life considerations in patients with advanced lung cancer: effect of topotecan on symptom palliation and quality of life. Oncologist. 2004;9(Suppl 6):14-24.

16. Henoch I, Bergman B, Gustafsson M, Gaston-Johansson F, Danielson E. The impact of symptoms, coping capacity, and social support on quality of life experience over time in patients with lung cancer. J Pain Symptom Manage. 2007;34(4):370-379.

17. Brown DJ, McMillan DC, Milroy R. The correlation between fatigue, physical function, the systemic inflammatory response, and psychological distress in patients with advanced lung cancer. Cancer. 2005; 103(2):377-382.

18. Nowicki A, Krzyminska J, Kowalewski J. Ocena jakości życia chorych leczonych operacyjnie z powodu raka płuca [Estimation of quality of life in patients after surgery for lung cancer]. Wspolcz Onkol. 2006;10(9):468-474. Polish.

19. Cooley ME. Quality of life in persons with non-small cell lung cancer: a concept analysis. Cancer Nurs. 1998;21(3):151-161.

20. Gift AG, Jablonski A, Stommel M, Given CW. Symptom clusters in elderly patients with lung cancer. Oncol Nurs Forum. 2004;31(2): 203-210.

21. Tishelman C, Degner LF, Mueller B. Measuring symptom distress in patients with lung cancer: a pilot study of experienced intensity and importance of symptoms. Cancer Nurs. 2000;23(2):82-90.

22. Butt Z, Rosenbloom SK, Abernethy AP, et al. Fatigue is the most important symptom for advanced cancer patients who have had chemotherapy. JNCCN. 2008;6(5):448-455.

23. Ostlund U, Wennman-Larsen A, Gustavsson P, Wengström Y. What symptom and functional dimensions can be predictors for global ratings of overall quality of life in lung cancer patients? Support Care Cancer. 2007;15(10):1199-1205.

24. Dagnelie PC, Pijls-Johannesma MCG, Lambin P, Beijer S, De Ruysscher D, Kempen GIJM. Impact of fatigue on overall quality of life in lung and breast cancer patients selected for high-dose radiotherapy. Ann Oncol. 2007;18(5):940-944.

25. Wachowicz M, Furmanik F. Ocena jakości życia chorych na (NDRP) niedrobnokomórkowego raka płuca leczonych chirurgiczne lub przedoperacyjną chemioterapią i następową resekcją [Quality of life assessment in patients with non-small cell lung cancer treated surgically or with preoperative chemotherapy followed by surgery]. Pneumonol Alergol Pol. 2003;71(3-4):121-131. Polish.

26. Zielinska-Wieczkowska H, Beltakowski J. Jakość życia pacjentów z chorobą nowotworową poddanych chemioterapii [Quality of life in cancer patients undergoing chemotherapy]. Wspolcz Onkol. 2010;14(3): 276-280. Polish.
27. Kubaszewska M, Skowronek J, Chichel A, Kanikowski M. The use of high dose rate endobronchial brachytherapy to palliate symptomatic recurrence of previously irradiated lung cancer. Neoplasma. 2008; 55(3):239-245.

28. Karczmarek-Borowska B, Pelc M, Rabiej E, Gradalska-Lampart M. Jakość życia chorych na niedrobnokomórkowego raka płuca poddanych chemioterapii [The quality of life of non-small cell lung cancer patients treated with chemotherapy]. Pneumonol Alergol Pol. 2014;82(4):349357. Polish.

29. Zabora J, BrintzenhofeSzoc K, Curbow B, Hooker C, Piantadosi S. The prevalence of psychological distress by cancer site. Psychooncology. 2001;10(1):19-28.

30. Carlsen K, Jensen AB, Jacobsen E, Krasnik M, Johansen C. Psychosocial aspects of lung cancer. Lung Cancer. 2005;47(3):293-300.

31. Montazeri A, Milroy R, Hole D, McEwen J, Gillis CR. Quality of life in lung cancer patients: as an important prognostic factor. Lung Cancer. 2001;31(2-3):233-240.

32. Hopwood P, Stephens RJ. Depression in patients with lung cancer: prevalence and risk factors derived from quality-of-life data. J Clin Oncol. 2000;18(4):893-903.

33. Li TC, Li CI, Tseng CH, et al. Quality of life predicts survival in patients with non-small cell lung cancer. BMC Public Health. 2012;12:790.

34. Pirl WF, Greer JA, Traeger L, et al. Depression and survival in metastatic non-small-cell lung cancer: effects of early palliative care. J Clin Oncol. 2012;30(12):1310-1315.

35. Kurowska K, Weilandt K. Sense of coherence and coping with the disease in patients with a diagnosis of lung cancer. Nurs Top. 2010; 1(1):11-16.

36. Porter LS, Keefe FJ, Garst J, McBride CM, Baucom D. Self-efficacy for managing pain, symptoms, and function in patients with lung cancer and their informal caregivers: associations with symptoms and distress. Pain. 2008;137(2):306-315.

37. Mock V, Atkinson A, Barsevick A, et al. NCCN practice guidelines for cancer-related fatigue. Oncology. 2000;14(11A):151-161.

38. Benzo RP. Pulmonary rehabilitation in lung cancer: a scientific opportunity. JCRP. 2007;27(2):61-64.

39. Sak J, Sagan D, Wiechetek M, Pawlikowski J. Suboptimal perception of illness due to self-realization constraints impairs psychological welfare in surgical patients. Eur J Cardiothorac Surg. 2012;41:824-828.
OncoTargets and Therapy

\section{Publish your work in this journal}

OncoTargets and Therapy is an international, peer-reviewed, open access journal focusing on the pathological basis of all cancers, potential targets for therapy and treatment protocols employed to improve the management of cancer patients. The journal also focuses on the impact of management programs and new therapeutic agents and protocols on

\section{Dovepress}

patient perspectives such as quality of life, adherence and satisfaction The manuscript management system is completely online and includes a very quick and fair peer-review system, which is all easy to use. Visit http://www.dovepress.com/testimonials.php to read real quotes from published authors. 